\title{
Estudo sobre As Paixões da Alma de René Descartes
}

\author{
Study on The Passions of the Soul of René Descartes
}

\author{
Heliakim Marques Trevisan \\ Graduando em Filosofia, Universidade Federal de São Carlos - UFSCar, São Carlos, SP, Brasil.
}

\begin{abstract}
Resumo: O presente artigo se desenvolve tendo como objetivo apresentar particularidades do livro As Paixões da Alma no interior do conjunto das obras de René Descartes. Por ser o derradeiro livro, apresenta questões que servem como resposta, ou mesmo síntese, aos problemas suscitados no decorrer de sua filosofia. O maior deles, provavelmente, o da união entre corpo e alma, é tratado aqui como tendo uma implicação, ao mesmo tempo, moral e fisiológica, mostrando, por conseguinte, a importância intrínseca que um objeto sem clareza e distinção adquire para Descartes no contexto de sua produção. Por isso, é mister assinalar o papel estratégico que este livro possui na produção cartesiana, como uma obra que, encerrando o pensamento do filósofo, deixa posta a questão desta união para a tradição que o sucedeu, tais como as filosofias do iluminismo, que tratarão a questão de maneira crítica ao pensamento cartesiano.
\end{abstract}

Palavras-chave: Racionalismo, mecanicismo, dualismo, modernismo, substância .

\begin{abstract}
This article is developed with the objective of presenting the particularity of the work Passions of the Soul within the set of the works of René Descartes. Because this book is the last, it presents issues that serve as a response, or synthesis, for the problems raised in the course of his philosophy. Perhaps the greatest of them, the union between body and soul, is treated in this text to have an implication at the same time moral and physiological, showing therefore the intrinsic importance of a no clarity object and distinction acquired for Descartes in this context. Therefore, it is necessary to point out the strategic role that this book has the Cartesian production as a work that, finishing the thought of the philosopher, lets put it this union to the tradition that succeeded him as the Enlightenment philosophies that treat the question critically the Cartesian thinking.
\end{abstract}

Keywords: Rationalism, mechanism, dualism, modernism, substance. 


\section{O significado de As Paixões da Alma compreendida como a última obra do pensamento cartesiano}

No decorrer de sua obra, René Descartes revela a preeminência de uma primeira certeza metafísica. O espírito seria o fundamento de todo conhecimento possível sobre o mundo, o que significa, como consequência de seu pensamento, que os dados dos sentidos como cores, odores, texturas, sons, não possuiriam qualquer objetividade, não apresentariam qualquer verdade intrínseca. Através da experiência sensível apenas nos seriam dados os estados sucessivos pelos quais passa nossa alma, mas de maneira alguma o conhecimento verdadeiro do ser ou do mundo. Com os sistemas racionalistas dava-se a possibilidade de esse conhecimento, a partir das ideias inatas do espírito, serem elementos inextensos desenvolvidos através da ciência. Assim, a objetividade de um dado colhido na experiência ganharia sua validade através de um processo no qual se passaria do extenso ao inextenso, do contingente ao necessário, enfim, do temporal ao atemporal, ao eterno. (CASSIRER, 1992, pg. 139). Seria, pois, uma via indireta em que este elo descontínuo seria assegurado por Deus, quem produz os elementos inextensos, ou a substância pensante. Desfigura-se o objeto progressivamente até que não sobre imagem ou elemento sensível algum. De certa forma, nega-se o objeto sensível para ganhá-lo em sua mais pura objetividade. Interioriza-se-o para conhecê-lo.

Todavia, em sua última obra, Descartes nos apresenta uma consideração nova com relação aos elementos da experiência. O Tratado das Paixões da Alma, ao mesmo tempo em que trata, sobretudo, de questões morais, trata de questões fisiológico-mecânicas. Aqui parece, portanto, ser o momento em que a substância extensa ganha um estudo específico na obra de Descartes, pois ela não será tratada de uma perspectiva clara e distinta, tal como podemos observar, por exemplo, nas obras $O$ mundo ou tratado da luz e os Princípios da filosofia, o que está em questão é o problema da união entre ela [substância extensa] e a substância pensante, pois é na união de ambas que se define a "natureza humana" e se estabelece assim os limites da moral cartesiana (TEIXEIRA, 1990, pg. 151). No contexto deste escrito, a substância extensa não é, portanto, abordada segundo a geometria, ou a física, o que não impede a investigação dos problemas morais a ela relacionados. Isto porque no plano da união do espírito com o corpo não há lugar para ideias claras e distintas. Daquela separação radical (extenso-inextenso) temos, nesta obra, a maneira como estas duas realidades poderiam juntar-se, e a maneira como abarcariam a totalidade da existência humana. Tal objeto, a coexistência de ambas, revela, então, seu caráter antes de tudo confuso, contingente, o que faz do Tratado não um exemplo teórico-científico da obra cartesiana, mas um estudo sobre a relação destes dois elementos de naturezas distintas. Além disso, um guia prático: vê-se aqui um esboço de uma moral cartesiana. Portanto, se o reconhecimento do corpo como objeto de estudo, neste contexto, não fornece conhecimento claro e distinto, ele, por sua vez, é a única via possível para uma vida feliz. A possibilidade de um governo sábio sobre o corpo será a condição da virtude e da felicidade.

Para tanto, é tratado neste artigo somente um trecho do Tratado das Paixões da Alma, a saber, a primeira parte, na qual são examinadas as teses que dizem respeito ao corpo, depois à alma, a união de ambas, e, por fim, o esboço de uma moral tendo em vista a natureza mista das paixões.

\section{Da separação e da união das substâncias pensante e extensa}

Nos primeiros artigos do tratado o autor começa evocando a diferença radical das naturezas: o que para o corpo é uma ação, para a alma é uma paixão. Paixão e ação seriam uma mesma coisa com nomes diferentes, referentes a cada uma das 
perspectivas. Portanto, é mister, para bem conhecer as paixões, distinguir as funções do corpo e da alma. No artigo dois aparece uma regra de distinção:

Tudo o que sentimos existir em nós, e que vemos existir também nos corpos inteiramente inanimados, só deve ser atribuído ao nosso corpo; e, ao contrário, que tudo o que existe em nós, e que não concebe de modo algum passível de pertencer a um corpo, deve ser atribuído a nossa alma. (DESCARTES, 1973, pg. 227)

Devemos, por conseguinte, considerar o movimento e o calor, por exemplo, como constituintes dos objetos inanimados e dos corpos, isto é, não pertencentes ao espírito $^{1}$. Pensamento, por sua vez, não pode existir nos objetos inanimados, mas numa natureza imaterial - substância pensante, ou inextensa. (art. 4) Logo, a alma não seria responsável pela geração de calor, como acreditavam os antigos, uma vez que objetos inanimados possuem calor, como o fogo, por exemplo. (art.5). No artigo sexto, Descartes finaliza a introdução afirmando do corpo vivo o caráter mecanicista. Concebe o corpo vivo como uma máquina complexa e autônoma em contraposição a um corpo morto, que seria tal como uma máquina fundida.

Do artigo sétimo ao décimo sexto são expostas as partes e as funções que dizem respeito ao corpo. Primeiramente é investigada a circulação do sangue e a geração de calor concentrada no coração, responsável pelos movimentos do corpo. O coração aparece aqui como o princípio motor do corpo, a causa material de sua autonomia. Em seguida: a produção dos espíritos animais; a maneira como os músculos se movem através deles; como se dão os movimentos reflexos e sua independência em relação à alma; como a diferença entre as qualidades dos espíritos provoca movimentos involuntários; como se dá, na composição deles, a diferença das qualidades; e, finalmente, como apenas os objetos dos sentidos, os órgãos do corpo e o curso dos espíritos animais não necessitam do intermédio da alma para mover o corpo, são asserções que reafirmam a caracterização mecânica do corpo na doutrina cartesiana.

Bem definidas as partes e as funções que dizem respeito ao corpo, bem como o processo pelo qual ele "funciona", esclarecida a complexidade do corpo vivo como substância extensa e sobretudo a maneira como suas partes se relacionam através de leis físicas e da linguagem matemática, o que reforça seu caráter extenso homogêneo ${ }^{2}$, o texto passa a tratar, a partir do artigo dezessete, as partes e as funções que dizem respeito à alma.

Do artigo dezessete ao trinta, o filósofo investiga as partes e as funções desta última. A primeira divisão corresponde a dois gêneros distintos: pensamentos que são ações da alma (art.18) e outros pensamentos que são paixões (art.19). Os pensamentos que são ações correspondem à nossas vontades e se dividem em outros dois: aqueles pensamentos que terminam na alma mesma, como, por exemplo, amar a Deus, ou a coisas não materiais; e aqueles pensamentos que terminam no corpo, como, por exemplo, movimentar as pernas e caminhar. Os pensamentos que são paixões da alma, que por sua vez são percepções, pois são todos os pensamentos que não são vontades, o que revela seu caráter passivo, possuem diversas divisões. A primeira divisão fundamental corresponde às percepções que têm a alma como causa e as percepções que têm o corpo como causa (art.20). As percepções que têm a alma como causa estão relacionadas às percepções das nossas atividades mentais: nossas vontades, imaginações. Já as percepções que têm o corpo como causa, possuem outras diversas

\footnotetext{
${ }^{1}$ (...) e, por não duvidarmos de que haja corpos inanimados que podem mover-se de tantas diversas maneiras que as nossas, ou mais do que elas, e que possuem tanto ou mais calor (o que a experiência mostra na chama, que possui, ela só, muito mais calor e movimento do que qualquer de nossos membros), devemos crer que todo o calor e todos os movimentos em nós existentes, na medida em que não dependem do pensamento, pertencem ao corpo. (DESCARTES, 1973, p. 228).

${ }^{2}$ Homogêneo no sentido de que todos são iguais, passíveis de se traduzir em grandezas matemáticas e leis da física (extensão, movimento e figura).
} 
divisões. A primeira está relacionada aos movimentos fortuitos dos espíritos animais (art.21), que são, também, corpos. Esses movimentos são responsáveis por produzir os sonhos, delírios, alucinações e etc. Eles não dependem dos nervos para tais coisas, mas apenas desses caminhos percorridos pelos espíritos animais. A segunda diz respeito àquelas percepções que estão diretamente relacionadas aos nervos (art.22), e se dividem em três: todas as sensações provindas dos objetos dos sentidos (art. 23); todas as sensações do nosso próprio corpo (art. 24), como, por exemplo, fome, cede, dor; e, a terceira, são as percepções da alma (art.25) que não têm como causa nem os objetos exteriores, nem as sensações do próprio corpo, mas que provêm da ação dos espíritos animais através dos nervos. Tais percepções, ademais, dizem respeito aos sentimentos de cólera, alegria, amor. À esta última classe Descartes assinala como a que melhor corresponde às Paixões da alma, pois se relaciona apenas com os estados da alma, ao mesmo tempo em que têm origem corpórea.

No artigo vigésimo sexto é apresentada a hipótese do sonho sobre estas últimas percepções. Segundo ele, independentemente do estado de vigília, tais paixões permanecem inalteráveis, uma vez que são independentes do objeto exterior, isto é, se fazem possíveis apenas pela representação na alma.

Ao cabo da exposição de como se dão as partes e as funções da alma, é exposto, no artigo vinte e sete, a definição no sentido estrito das Paixões: "(...) podemos em geral defini-las por percepções, ou sentimentos, ou emoções da alma, que referimos particularmente a ela, e que são causadas, mantidas e fortalecidas por algum movimento dos espíritos." (DESCARTES, art.27, 1973)

No artigo vinte e oito e vinte e nove, temos a explicação em duas partes dessa definição. Na primeira parte, as paixões podem ser chamadas percepções, por que evidenciam todos os pensamentos que não são ações ou vontades. Podem, também, ser chamadas sentimentos, pois chegam à alma assim como os objetos dos sentidos, porém o termo que melhor expressa sua definição é emoção. Isto porque este termo expressa maior intensidade dos sentimentos e, consequentemente, maior passividade da alma. A segunda parte reforça o que já foi dito: sua origem, apesar de ser corporal - espíritos animais - só se relaciona à alma (alegria, amor, ódio), ou seja, não diz respeito aos objetos exteriores, nem aos órgãos do corpo. Por esse motivo o termo "emoções" é melhor empregado, pois se relaciona apenas com a alma.

O que fica evidente neste primeiro trecho é o objetivo de Descartes ao mostrar qual é a natureza das paixões e a qualidade das ideias que delas podemos ter. A conclusão destes objetivos é que não se pode estudar as paixões a não ser no plano da união substancial entre a alma e o corpo, isto é, um conhecimento que não ultrapassa o plano das ideias confusas. (TEIXEIRA, 1990, pg. 172)

Assim, no artigo trinta, ao mesmo tempo que encerra a exposição a respeito da alma, introduz, finalmente, sua relação com o corpo, mostrando como a alma se encontra unida verdadeiramente ao corpo todo, uma vez que não possui dimensão extensa. A tese concretiza-se a partir do artigo trinta e um com a glândula pineal, que é o órgão responsável pela conexão entre as duas substâncias. Por ser o único órgão no cérebro que não possui duas partes, e por seu posicionamento estratégico (art.34) - lugar muito privilegiado por onde os espíritos permanecem antes e depois de percorrer o corpo -, Descartes infere que é neste órgão que as impressões duplas de todo o corpo se convergem e se unificam produzindo as representações, duplicando o mundo, diria Bergson (BERGSON, 1974, pg. 49) (art.35). As impressões dos sentidos trazidas pelos espíritos através dos nervos vêm calhar na região desta glândula. Este órgão seria a sede principal da alma, responsável pela tarefa primordial de conectar as duas naturezas distintas: a mente e o corpo, de maneira que o corpo, através dos espíritos, movimentaria a glândula, que produziria as representações para a alma, assim como a alma movimentaria a glândula, articulando o movimento dos espíritos e o consequente movimento do corpo. 
Como nos diz o Prof. Lívio Teixeira, Descartes, neste contexto, não apresenta qualquer princípio racional para explicar a união e os processos de interdependência entre corpo e alma, pois o argumento que leva a definir a glândula pineal como sede da união, através de disposições anatômicas do cérebro e da fisiologia dos espíritos animais, não constitui, de fato, uma explicação (TEIXEIRA, 1990, pg. 174). A união é um fato que "a experiência torna evidente para cada homem" (Idem). Descartes renuncia a essa explicação porque não é este o objetivo deste contexto, e sim o conhecimento que se dá a partir da natureza humana já entendida como composição que encontra sua união substancial. Será somente a partir desta união que se poderá abordar as paixões.

Assim explicitado, podemos, a partir de então, do artigo trinta e seis em diante, esclarecer de que forma as paixões, que têm por origem o corpo, podem se relacionar à alma, e como, por isso, se tornam confusas, não possuindo nem clareza nem distinção, não podendo, portanto, jamais ser objeto da ciência. Como afirma o professor Lívio Teixeira:

No que diz respeito à moral, uma vez que as paixões são fenômenos que se passam no plano da união, a impossibilidade de uma explicação científica desta, por meio de ideias claras e distintas, lança todo o tratamento do assunto no plano das ideias confusas. (TEIXEIRA, 1993, pg. 174).

Isto, não obstante, é de suma importância, uma vez que, tornar o estudo das paixões um conhecimento que não é nem claro nem distinto, revela a irredutibilidade do conhecimento da natureza humana ao conhecimento científico, mostrando o quão valioso se torna um estudo da moral neste sentido. Isso se evidencia por uma mesma situação causar efeitos diferentes a indivíduos diferentes. Através das paixões, a relação entre a alma e o corpo ganha um sentido específico. A alma sente e quer o que o corpo está preparado para realizar. Desta forma, através do conhecimento desta união, tornar-se-á possível esboçar um método de domínio, ou ao menos de orientação, em relação às paixões.

Observa-se, assim, no artigo trinta e seis, que são determinadas situações que, levando os espíritos a mover a glândula, causam determinadas sensações à alma, que produzirá determinadas emoções ou paixões. Com efeito, a mesma situação faz com que indivíduos tenham paixões diferentes, por exemplo, numa mesma situação de perigo dois homens tomando maneiras distintas de reagir. É, pois, este caráter incerto das paixões que as impossibilita de ser objeto da ciência. Ademais, as paixões têm a qualidade, entre outras coisas, de movimentarem o corpo independente da alma. Apenas pelos órgãos dos sentidos a paixão age sobre o corpo, sem que a alma contribua. Isso é ainda mais visível no artigo quarenta, no qual é revelado o principal efeito das paixões:

Pois cumpre notar que o principal efeito de todas as paixões nos homens é que incitam e dispõem a sua alma a querer as coisas para as quais elas lhes preparam os corpos; de sorte que o sentimento de medo incita a fugir, o da audácia a querer combater e assim por diante. (DESCARTES, 1973, pg. 242).

Eis, portanto, o caráter negativo das paixões: nos remetem a atitudes incontroláveis, uma vez que a paixão influencia diretamente nossas ações sem recorrer ao espírito, tornando passivo este último. Podemos combater as paixões através de outra parte da alma: a vontade. É no momento em que movemos a glândula que podemos lutar contra as paixões. No artigo quarenta e cinco percebemos que a vontade não pode excitar, diretamente, uma paixão, no entanto é possível combatê-la indiretamente: podemos reproduzir, através da vontade, uma representação que cause uma paixão contrária. Quando se está com medo de uma briga, por exemplo, basta pensar que será mais vergonhoso fugir. Isso dará coragem para enfrentar o medo e combater a primeira 
paixão. Portanto, é colocando uma representação ao lado da outra que combatemos paixões. (DESCARTES, 1992, Pg. ,244). Se a paixão permanece, ela pode também estar sendo mantida pelos espíritos animais: os espíritos animais continuam percorrendo o mesmo caminho. Assim, de outra maneira, se somos ainda importunados por ela, podemos, perseverantemente, combatê-la também com a nossa vontade através da paralisação dos nossos movimentos. (DESCARTES, 1992, Pg. 244)

Ademais, quando as duas potências primordiais do homem forem contrárias, teremos a disputa entre a alma e o corpo, onde a mais forte será vitoriosa, sendo a mais fraca impedida de agir. O indivíduo, no caso em que não tem condições de lutar contra o corpo através das representações, querendo duas coisas ao mesmo tempo, se vê, assim, em plena contradição. A partir disso é que se poderá distinguir as almas fortes das fracas (DESCARTES, 1992, pg. 246). Sendo estas últimas aquelas que nem sequer lutarão contra os ditames da paixão, não serão senão escravas das próprias paixões, escravas da contingência, da contradição, da irracionalidade. As almas fortes, por outro lado, serão aquelas capazes de lutar e resistir contra as paixões, através do domínio da alma.

Descartes finaliza, curiosamente, o último artigo da primeira parte do Tratado depois de mencionar que, para o domínio das paixões da alma, não é necessária uma alma munida da verdade. A noção de cartesiana de virtude se relaciona, neste sentido, a uma aplicação ou desenvolvimento de um esforço de bem pensar e bem agir, pois que tal esforço é a sobreposição de "um complexo de ligações adquiridas artificialmente pela repetição" sobre o "complexo das ligações naturais entre os movimentos dos espíritos e determinados estados de consciência" (TEIXEIRA, 1990, pg. 179), isto é, as necessidades vitais do homem. É por ser um esforço em bem agir e pensar, segundo uma concepção de bem e mal, que tal atitude pode definir-se como virtude. Dirá Descartes, como exemplo, que tal domínio pode ser adquirido, antes, por um cão adestrado, como os cães perdigueiros (DESCARTES, 1992, pg. 247), que são treinados para resistir aos próprios instintos: aprendem a não atacar a presa e nem fugir quando do ruído do tiro. Ou seja, o governo total sobre as paixões pode ser adquirido pelo hábito, pelo agir bem através da repetição. É através da disciplina, enquanto hábito e repetição, que podemos governar as paixões. E mesmos aqueles mais fracos de alma e afastados da verdade do conhecimento racional, podem ter total controle sobre suas paixões.

\section{Considerações finais}

Bem definidas as maneiras como o ser humano pode lutar contra as paixões, percebe-se a solução na convergência daquela distinção radical. O objeto investigado aqui deriva de duas concepções irredutíveis, a saber, substancia extensa e substância pensante. Se tal separação encerra toda a filosofia cartesiana, tendo uma forte influência sobre os problemas colocados pelos pensadores do século XVII, em contrapartida a questão primordial nesta obra é: a importância da compreensão da união delas para o estudo das paixões. Sabemos que o corpo não é fonte de conhecimento claro e distinto, uma vez que se constitui de um misto, porém, na sua ausência não haveria o estudo dos elementos das paixões, como o amor, a alegria ou a cólera. O papel fundamental das paixões está relacionado, portanto, à grande necessidade de se perceber a união entre as duas naturezas tão bem divididas, a ponto de a virtude ser achada no controle delas. Em suma, a investigação a respeito da moral não seria possível sem a consideração dos corpos materiais e, apesar de ser um conhecimento confuso, ela aponta para um sumo bem no terreno da experiência. A moral cartesiana esboçada nesta obra é, portanto, a busca da virtude e da felicidade através das ações 
e o bem deliberar da alma - vontade - sobre as paixões que, por sua vez, dependem das regiões confusas e imperfeitas do vivido: o externo, o inexato enfim.

A preocupação voltada para os dados materiais mostra, no Tratado das Paixões da Alma, uma tendência na filosofia cartesiana que, de certa forma, prenunciava todo o pensamento posterior, fosse para afirmá-lo, fosse para recusá-lo. Como diz Cassirer, toda a filosofia do iluminismo girará em torno de um problema comum: o vínculo entre o problema da natureza e o problema do conhecimento. E desta forma, em seu espírito, o iluminismo recusará veementemente o racionalismo cartesiano. Em outras palavras, haverá, nesta tradição, a tendência a suprimir a intermediação entre a impressão sensível e o sujeito. O Tratado, assim, é a derradeira obra de um autor que levantou um edifício teórico e cultural no ocidente e, como um dos pais do pensamento moderno, apontando, ademais, a radicalidade de duas naturezas irredutíveis, mostra nesta obra não uma redutibilidade de ambas, mas certamente uma possível compreensão da união das substâncias para o desenvolvimento de uma moral. Seria talvez precipitado afirmar desta obra a causa para a tradição que a sucedeu, mas certamente afirmamos a influência introduzida de questões elementares que seriam tratadas na filosofia do iluminismo, seja pela colocação dos problemas, seja pela falta de suas respostas.

Correspondência: Heliakim Marques Trevisan. Universidade Federal de São Carlos - UFSCar, Rodovia Washington Luís, Km 235, s/n, Jardim Guanabara, CEP13565-905, São Carlos, SP, Brasil. E-mail: heliakim_trevisan@hotmail.com Conflito de interesses: Nenhum. 


\section{Referências}

DESCARTES, René. As paixões da alma. Introd. de G.-G. Granger; pref. e notas de G. Lebrun; trad. de J. Guinsburg e B. Prado Jr. São Paulo: Abril Cultural, 1973 (col. Os Pensadores).

TEIXEIRA, Lívio. Ensaio sobre a moral de Descartes. São Paulo: Secret. de Est. da Cultura, Brasiliense, $2^{\mathrm{a}}$ ed. 1990.

CASSIRER, Ernst. A Filosofia do Iluminismo. Tradução: Alvaro Cabral - Campinas, SP: Editora da UNICAMP, 1992. (Coleção Repertórios)

BERGSON, Henri. Os Pensadores / O Cérebro e o Pensamento: Uma Ilusão Filosófica. Tradução: Franklin Leopoldo e Silva - São Paulo, SP: Abril SA, 1974.

ALQUIÉ, Ferdinand. A filosofia de Descartes. Lisboa: Presença, 1980.

GUENANCIA, Pierre. Descartes. Rio de Janeiro: Jorge Zahar, 1991. 